\title{
Stress and ego-defense mechanisms in medical staff at oncology and physical medicine departments
}

\author{
Kocijan Lovko Sandra* \\ Gregurek Rudolf** \\ Karlovic Dalibor ${ }^{\star * *}$ \\ * Psychiatry Outpatient Department, General \\ Hospital Zabok, Zabok \\ ** Department of Psychological Medicine, \\ University Hospital Zagreb, School \\ of Medicine, University of Zagreb, Zagreb \\ *** Psychiatry Department, Clinical Hospital \\ "Sestre milosrdnice", University of Zagreb, \\ Zagreb
}

CROATIA

\begin{abstract}
Background and Objectives: Work on the oncology department has proved to be very stressful, so the medical staff indirectly copes with it by trying to escape it through the ego-defense mechanisms. On the other hand, working on the physical medicine department does not seem to be so stressful. The objective of this study was to determine the main ego- defense mechanisms at oncology and physical medicine department and to explain the differences between their frequencies. The other part was to obtain data about socio- demographic status and working environment of the participants.

Methods: General structural interview for collecting data on socio-demographic status and working environment and Life Style Questionnaire and Defense Mechanisms for obtaining data about ego-defense mechanisms were carried out among a random sample of 40 medical staff members at each department.

Results: A significantly higher level $(\mathrm{p} \leq .05)$ of the following ego-defense mechanisms has been found at the oncology department: regression, intellectualization, projection and dislocation. Also, statistically significant difference ( $\mathrm{p} \leq .05)$, showing higher score on oncology department is observed in following variables: death of patients, facing the patient or his family with possible death, being overloaded with number of patients, facing pain, suffering and handicap, insufficiency of medications, insufficient positive feedback from the patients and bad interpersonal relations at work as well as lack of support from the colleagues.

Conclusions: Extreme exposure to stressful events at the oncology department favours development of inadequate defensive mechanisms among the medical staff, which may enhance the risk of burnout.
\end{abstract}




\section{Introduction}

There is a growing awareness within medicine that physicians and other health care professionals are at risk for burnout, which threatens the sustainability of the health care enterprise1-5. Recent changes in health care delivery have added new demands to already stressful work of medical staff 6-8. Among many striking staff complaints are those that clearly indicate the presence of underlying feeling of anxiety, guilt, disappointment, and helplessness.

In 1936, Freud defined ego-defense mechanisms as mental functions that protect the individual from the excessive anxiety deriving from both stressful external events and disruptive inner psychological states. Protective property of ego-defense mechanisms acts through modification, distortion or removal of stressful thoughts, feelings and perceptions ${ }^{9}$.

According to Plutchik's theory of emotion, basic human emotions evoke ego defenses and coping styles ${ }^{10}$. Ego-defense mechanisms operate on a subconscious level to resolve or conceal conflicted emotions and anxieties, whereas coping styles are cognitive responses that allow an individual to adapt to conflicted emotions and stress. The strategies some people use when faced with the stress of interacting with a diseased individual can be understood within the framework of Plutchik's theory, and can be divided into two major categories: those that impose physical distance, primarily through avoidance of the diseased person, and those that impose psychological distance by delegitimizing emotions expressed by the diseased person.

Many authors have pointed out that work at the oncology department represents a particularly very stressogenic factor which leads to the development of burnout in the long run ${ }^{11-14}$, as a state of mental or physical exhaustion ${ }^{15}$. Burnout is the result of a severe, protracted stress, for which the individual's usual coping skills have become ineffective ${ }^{16,17}$

The specific features of this work, including the frequent encounters with death, inspire the medical staff to contemplate their own mortality and unconsciously stimulate thoughts about boundaries of time, possible mistakes and failures in treatment ${ }^{18}$. Besides that, particularly among doctors, there is a significant influence of compulsive triad, consisting of suspicion, guilt and exaggerated feeling of responsibility ${ }^{19}$, undoubtedly leading towards using more immature defense mechanisms, aimed at maintaining persons integrity in such extremely stressful circumstances. Opposite to the oncology departments, work at the departments of physical medicine does not seem so stressful, due to the domain of the profession itself and study confirming medium- low level of burnout among physical rehabilitation professionals ${ }^{20}$. Our hypothesis was that the defense mechanisms at the oncology department, due to the circumstances described above, would be more immature compared to the department of physical medicine. The aim of this study was to investigate defense mechanisms among the staff at the departments of oncology and physical medicine and explore and explain the differences in their use and to obtain data about sociodemographic status and working environment of the participants.

\section{Subjects and methods}

\section{Sample}

The sample consisted of 40 staff members, including doctors $(\mathrm{N}=13)$ and nurses 
( $N=27)$ from the department of oncology at University Hospital Zagreb and 40 staff members from the department of physical medicine, rehabilitation medicine and rheumatic diseases at Polyclinic Dr. Drago Čop, Zagreb, including doctors $(\mathrm{N}=11)$, nurses and physiotherapists $(\mathrm{N}=29)$. This Polyclinic is the largest one in Zagreb and deals with the wide range of rheumatic diseases and also a degenerative diseases of locomotor's system and rehabilitation after trauma and consequent operative procedures. The number of subjects has been determined according to the average number of employees working for both departments. The questionnaires have been distributed among them randomly during the year 2004 . We have found no significant differences of age between the subjects working at the oncology department and the subjects working at the department for physical medicine because their mean age approximately matched (Table I). It is also visible that there were no significant differences in duration of work between the subjects from oncology and subjects from physical medicine, because their work experience was similar (Table I). Moreover, the groups were also similar according to sex, i.e. the number of female subjects equaled at the oncology department and at the physical medicine department (Table I).

In the sample informed consent was obtained, in respect of the right to privacy. The study has been undertaken in a manner consistent with the guidelines of the World Health Organization and the declaration of Helsinki.

\section{Questionnaires}

We have used a general structural interview in order to collect data on socio-demo- graphic status and working environment of the participants (age, work experience, sex, marital status, 9 later described stressors at work, working in shifts, support from other people) and the Life Style Questionnaire.

Life Style Questionnaire and Defense Mechanisms ${ }^{21}$ is based on Plutchik's theory of eight primary emotions which are connected to eight basic defense mechanisms (reactive formation-joy, negation-acceptance, regression-surprise, suppression-fear, compensation-sadness, projection-rejection, intellectualization-expectance, dislocationanger), which are crucial for keeping those emotions under control. An evaluation of psychometric characteristics of this method has already confirmed its high reliability in our population ${ }^{22}$.

\section{Statistical methods}

Results of the study were submitted to statistical analysis by use of the Windows SPSS program. In the statistical analysis of our data, we used descriptive statistics to describe analyzed variables in both groups of subjects, from oncology and physical medicine. The parametric variables have been described as average values and standard deviations (age, work experience, number of positive answers concerning the defense mechanisms) and particular defense mechanisms have been described as ranges and medians. Non-numeric variables have been described as frequencies and percentages from the total number of patients in each group of subjects tested. Non-parametric methods were used to compare variables sex (Chi-square test) and differences of using the particular defense mechanisms (Mann-Whitney U Test). Before calculating the statistical significance of the differences observed for 
Table I

Results from general structural interview on socio-demographic status and working environment in medical staff on oncology department $(N=40)$ and physical medicine department $(N=40)$.

\begin{tabular}{|c|c|c|c|c|}
\hline Variable & $\begin{array}{l}\text { Oncology } \\
\text { No. }(\%)\end{array}$ & $\begin{array}{c}\text { Physical medicine } \\
\text { No. }(\%)\end{array}$ & $\mathrm{t}^{1} /$ Chi- $_{\text {square }}{ }^{2}$ & $\mathrm{p}$ \\
\hline Age in years /mean $\pm \mathrm{SD} /$ & $36.4 \pm 11.63$ & $38.8 \pm 11.86$ & $0.904^{1}$ & 0.369 \\
\hline Working experience in years/mean $\pm \mathrm{SL}$ & $14.9 \pm 11.01$ & $16.8 \pm 11.54$ & $0.753^{1}$ & 0.453 \\
\hline \multicolumn{5}{|l|}{ Sex } \\
\hline Female & $36(90.0)$ & $38(95.0)$ & $0.721^{2}$ & 0.960 \\
\hline Male & $4(10.0)$ & $2(5.0)$ & & \\
\hline \multicolumn{5}{|l|}{ Marital status } \\
\hline Married & $24(60.0)$ & $24(60.0)$ & & \\
\hline Single & $11(27.5)$ & $11(27.5)$ & $1.111^{2}$ & 0.893 \\
\hline Divorced/widowed & $5(12.5)$ & $5(12.5)$ & & \\
\hline \multicolumn{5}{|l|}{ Stress 1} \\
\hline Yes & $17(42.5)$ & 0 & $21.587^{2}$ & $<.001$ \\
\hline No & $23(57.5)$ & $40(100)$ & & \\
\hline \multicolumn{5}{|l|}{ Stress 2} \\
\hline Yes & $17(42.5)$ & $1(2.5)$ & $18.351^{2}$ & $<.001$ \\
\hline No & $23(57.5)$ & $39(97.5)$ & & \\
\hline \multicolumn{5}{|l|}{ Stress 3} \\
\hline Yes & $29(72.5)$ & $16(40.0)$ & $8.584^{2}$ & 0.003 \\
\hline No & $11(27.5)$ & $24(60.0)$ & & \\
\hline \multicolumn{5}{|l|}{ Stress 4} \\
\hline Yes & $7(17.5)$ & $3(7.5)$ & $1.829^{2}$ & 0.176 \\
\hline No & $33(82.5)$ & $37(92.5)$ & & \\
\hline \multicolumn{5}{|l|}{ Stress 5} \\
\hline Yes & $3(7.5)$ & $8(20.0)$ & $2.635^{2}$ & 0.105 \\
\hline No & $37(92.5)$ & $32(80.0)$ & & \\
\hline \multicolumn{5}{|l|}{ Stress 6} \\
\hline Yes & $18(45.0)$ & $8(20.0)$ & $5.698^{2}$ & 0.017 \\
\hline No & $22(55.0)$ & $32(80.0)$ & & \\
\hline \multicolumn{5}{|l|}{ Stress 7} \\
\hline Yes & $34(85.0)$ & $8(20.0)$ & $33.885^{2}$ & $<.001$ \\
\hline No & $6(15.0)$ & $32(80.0)$ & & \\
\hline \multicolumn{5}{|l|}{ Stress 8} \\
\hline Yes & $5(12.5)$ & $17(42.5)$ & $9.028^{2}$ & 0.003 \\
\hline No & $35(87.5)$ & $23(57.5)$ & & \\
\hline \multicolumn{5}{|l|}{ Stress 9} \\
\hline Yes & $30(75.0)$ & $7(17.5)$ & $26.600^{2}$ & $<.001$ \\
\hline No & $10(25.0)$ & $33(82.5)$ & & \\
\hline \multicolumn{5}{|l|}{ Working in shifts } \\
\hline Yes & $18(45.0)$ & $14(35.0)$ & $0.833^{2}$ & 0.361 \\
\hline No & $22(55.0)$ & $26(65.0)$ & & \\
\hline \multicolumn{5}{|l|}{ Support } \\
\hline \multicolumn{5}{|l|}{ From colleagues } \\
\hline Yes/no & $10(25.0) / 30(75.0)$ & $22(55.0) / 18(45.0)$ & $7.500^{2}$ & 0.006 \\
\hline \multicolumn{5}{|l|}{ From friends } \\
\hline \multirow{2}{*}{\multicolumn{5}{|c|}{ From family }} \\
\hline & & & & \\
\hline Yes/no & $20(50.0) / 20(50.0)$ & $23(57.5) / 23(57.5)$ & $0.000^{2}$ & 1.000 \\
\hline \multicolumn{5}{|l|}{ Without support } \\
\hline Yes/no & $6(15.0) / 34(85.0)$ & $2(5.0) / 38(95.0)$ & $2.222^{2}$ & 0.136 \\
\hline
\end{tabular}


parametric variables (age and work experience), normality of distribution in both groups had been determined by means of Kolmogoroff-Smirnoff test. The statistical significance for the differences of variables described above has been determined by means of Student t-test. The statistical significance has been set to $5 \%(\mathrm{p}=0.05)$.

\section{Results}

There is no statistically significant difference in age range, working experience, sex and marital status, between medical staff on oncology department and medical staff on physical medicine department (Table I). Regarding unclear professional role, insufficient autonomy in making decisions, working in shifts as well as support (from friends, family and also being without support) there is no statistically significant difference between the two observed groups (Table I). Statistically significant difference, showing higher score on oncology department is observed in following variables: death of patients, facing the patient or his family with possible death, being overloaded with number of patients, facing pain, suffering and handicap, insufficiency of medications, insufficient positive feedback from the patients and bad interpersonal relations at work as well as lack of support from the colleagues (Table I).

Table II. shows that there is a statistically significant difference in using the defensive mechanisms of regression, intellectualization, projection and dislocation, meaning that these mechanisms are more frequently used at the oncology department opposite to physical medicine department. There is no statistically significant difference in using the defensive mechanisms of reactive formation, negation, suppression and compensation.

\section{Discussion}

In our research, we have tried to examine interaction of health professionals egodefense mechanisms and socio- demographic characteristics as well as working environment. Hospital workers dealing with severely damaged physically handicapped patients are subject to more frequent and more intense personal distress than staff treating less seriously ill patients. In our

Table II

Results from Life Style Questionnaire and Defense Mechanisms in medical staff on oncology department $(\mathrm{N}=40)$ and physical medicine department $(\mathrm{N}=40)$.

\begin{tabular}{lcccccc}
$\begin{array}{l}\text { Ego-defense } \\
\text { mechanisms }\end{array}$ & $\begin{array}{c}\text { Range } \\
\text { (min-max) }\end{array}$ & $\begin{array}{c}\text { Oncology physical medicine } \\
\text { Median }\end{array}$ & $\begin{array}{c}\text { Range } \\
\text { (min-max) }\end{array}$ & Median & Z & $\mathrm{p}$ \\
\hline Reactive formation & $(0-5)$ & 2 & $(0-5)$ & 2 & 0.961 & 0.337 \\
Negation & $(0-9)$ & 5 & $(2-10)$ & 5.5 & 1.035 & 0.301 \\
Regression & $(1-8)$ & 4.5 & $(0-12)$ & 3.5 & 2.353 & 0.019 \\
Suppresion & $(0-5)$ & 2 & $(0-6)$ & 2 & 1.731 & 0.084 \\
Compensation & $(0-6)$ & 3 & $(0-8)$ & 3 & 1.259 & 0.208 \\
Projection & $(4-8)$ & 6 & $(2-8)$ & 5 & 3.747 & $<0.05$ \\
Intellectualization & $(4-10)$ & 7 & $(4-11)$ & 8.5 & 2.839 & 0.005 \\
Dislocation & $(0-6)$ & 4 & $(0-8)$ & 1 & 4.724 & $<0.05$ \\
\hline
\end{tabular}


study we found that medical staff on oncology is affected with more stressors (7 out of 9 including death of patients, facing the patient or his family with possible death, being overloaded with number of patients, facing pain, suffering and handicap, insufficiency of medications, insufficient positive feedback from the patients and bad interpersonal relations at work) and that they do not have support from the colleagues compared with medical staff on physical medicine department and these findings support the results of other studies that report about stress on oncology department ${ }^{14,23,24}$. There was no statistically significant difference in having a support from friends and family as well as being without support. To deal with stress, people use both intentional, consciously willed behaviors (coping) and also unconscious mechanisms (defenses) ${ }^{25}$.

In our study, we have found no statistically significant differences in use of the defensive mechanisms of reactive formation, negation, suppression and compensation, which are all neurotic mechanisms except negation that is according to Vaillant immature, i.e. both groups of our subjects use these mechanisms in similar measure ${ }^{25}$. There is a significant difference in use of the remaining four defensive mechanisms: regression, intellectualization, projection and dislocation, which are significantly more frequently used by the medical staff at the oncology department. There are no previous researches on the use of the different ego- defense mechanisms at any oncology and physical medicine department.

Regression, or the return to a previous state, represents returning from more developed and more organized level of behavior to earlier ways of behaving, which does not suit the chronological age of the person. Kellerman's description of regression matches the description of tendency towards impulsive reactions, which belong in a group of immature defenses ${ }^{21}$. Significantly more frequent use of this particular mechanism of defense can be understood in the context of permanent exposure to high levels of stress, where this type of defense prevents destruction of self and enables individual to function normally. According to Vaillant this mechanism belong to the group of immature ego defense mechanisms in contrast to neurotic mechanism intellectualization whose significantly higher level of use is found at oncology department ${ }^{25}$.

This particular defense mechanism is aimed to explain some reaction afterwards, using reasons that not only justify the reaction, but also cover the real motives. At the department of oncology, where meeting the serious, often terminally ill patients is frequent, avoidance of empathy and later explaining this reaction with large number of patients and lack of time represents a frequent mechanism of "survival".

The compulsive triad, mentioned in the introduction (suspicion, guilt and the exaggerated feeling of responsibility), particularly found among doctors in already described specific working conditions of the oncology department, exhausts individual in the long run, leading towards the development of anger, which is most easily controlled by means of directing it towards something else $^{19}$. That causes the occurrence of dislocation. Dislocation is aimed towards the reduction of a subconscious fear and consists of releasing the impulses or subconscious fantasies by means of transferring them from one object to the other. The unpleasant feeling is suppressed concerning the object that caused it and released in the relation to another object or person. The mechanism of projection, which is actually a result of an insufficient suppression, is also connected with this. It is known that the 
projected feelings are those unacceptable to superego, like anger or aggression. Thus, projection, or the intent transferred to another person, represents a mechanism by means of which a person connects its own wishes, feelings, fantasies and urges to other people. Projection represents a failure of suppression, because its purpose is, if the other defenses fail to suffice, to turn the inner danger to outer, which is then fought using the most archaic defensive means, with dislocation and avoiding. Projection, according to Vaillant, belongs to the group of immature mechanisms and dislocation to the group of neurotic. According to Kellerman displacement is immature mechanism of defense, so in our context "working in pair" with immature projection can be treated as such $^{21,25}$. The permanent exposure to stress at the oncology department gets perceived by individual in different manners, varying in spectrum from accepting the stress as a challenge to its suppression and distorting the reality by means of using the defensive mechanisms. Accepting the permanent stress as a challenge represents a significant effort to medical staff and largely depends on its appraisal. Many theoreticians believe that individual's response to a stressor is a function of: 1. Primary appraisal in which stressor is constructed as either a threat or as a challenge and 2. Secondary appraisal in which individual decides if he or she has the coping resources to deal effectively with stressor $^{26}$. In cases where the conscious mechanisms of coping with stress fail, i.e. when a person believes that he has no necessary coping skills or feels too exhausted to activate them every time when they are needed, dealing with stress continues subconsciously by means of activating the defense mechanisms. In the situations of exposure to the terminally ill patients, death or overload of seriously ill patients, the most frequently used neurotic defensive mechanisms fail to suffice (suppression, for example), and need to be reinforced by activating immature and some other neurotic mechanisms, in this case it is intellectualization, aimed at justifying certain reactions and deeds, or regression, aimed at moving away from everyday stress.

The results obtained and the phenomena observed point out the importance and interrelation in use of regression, intellectualization, projection and dislocation, defensive mechanisms that belong among neurotic and immature defenses, indicating extreme exposure to stressful events at the oncology department, which causes development of these inadequate defensive mechanisms among the medical staff. Certain personality traits, such as defense mechanisms, may enhance the risk of burnout by influencing the individual's response to stressors in the workplace $^{27}$ so our next goal will be to explore the level of burnout in the two observed groups.

Since the defensive mechanisms represent a product of our unconscious functioning, we can conclude that these persons keep on using such defensive mechanisms in their everyday life situations, outside the working environment, which may result in dysfunction and the reduction of quality of life. Moreover, the results of our study indicate the necessity of psychotherapeutic support, i.e. activities aimed to reduce the exposure to burnout.

\section{References}

1. Grau A, Suner R, Garcia MM, et al. Burnout syndrome in health workers and relationship with personal and environmental factors. Gac Sanit 2005; 19(6): 463470. 
2. Albar Marin Ma J, Garcia-Ramirez M. Social support and emotional exhaustion among hospital nursing staff. Eur J Psychiat 2005; 19(2): 96-106.

3. Lyckholm L. Dealing with stress, burnout, and grief in the practice of oncology. Lancet Oncol 2001; 2: 750755.

4. Baider L, Wein S. Reality and Fugues in Physicians facing death: confrontation, coping, and adaptation at the bedside. Crit Rev Oncol Hemat 2001; 40: 97-103.

5. Spickard A, Gabbe G, Christensen JF. Mid-career burnout in generalist and special physicians. JAMA 2002; 25: $1447-1450$

6. Zuger A. Dissatisfaction with medical practice. New Engl J Med 2004; 350: 69-75.

7. McManus IC, Keeling A, Paice E. Stress, burnout and doctors' attitudes to work are determined by personality and learning style: A twelve year longitudinal study of UK medical graduates. BMC Med 2004; 2: 29-41.

8. McManus IC, Winder BC, Gordon D. The causal links between stress and burnout in a longitudinal study of UK doctors. Lancet 2002; 359: 2089-2090.

9. Freud A. The ego and the mechanisms of defense. New York: International Universities Press; 1936.

10. Plutchik R, Kellerman H, Conte HR. A structural theory of ego defenses and emotions. In: Izard CE, editor. Emotions in personality and psychopathology. New York: Plenum Press; 1979.

11. Whippen DA, Canellos GP. Burnout syndrome in the practice of oncology: results of a random survey of 1,000 oncologists. J Clinic Oncol 1991; 9: 1916-1921.

12. Ramirez AJ, Graham J, Richards MA, Timothy AR. Stress at work for the clinical oncologists. Clinic Oncol 1996; 8: 137-139.

13. Kash KM., Holland JC, Breitbart W, Berenson S, Dougherty J, Oulette-Kobasa S, et al. Stress and burnout in oncology. Oncol 2000; 14: 1621-1633.

14. Akroyd D, Caisson A, Adams RD. Burnout in radiation therapists: the predictive value of selected stressors. Int J Radiat Oncol 2002; 52: 816-821.

15. Girdino DA, Everly GS, Dusek DE. Controlling Stress and Tension, Needham Heights: Allyn \& Bacon; 1996.
16. Maslach C. Burout The Cost of Caring. New York: Prentice-Hall; 1982.

17. Maslach C, Schaufeli WB, Leiter MP. Job burnout. Annu Rev Psychol 2001; 52: 397-422.

18. Rousseau P. Caring for the dying: Why is it so hard for physicians? Western J Med 2001;17: 284-285.

19. Gabbard GO. The Role of Compulsiveness in the Normal Physician. JAMA. 1985; 254: 2926-2929.

20. Li Calzi S, Farinelli M, Ercolanti M, Alianti M, Manigrasso V, Taroni AM. Physical rehabilitation and burnout: different aspects of the syndrome and copmparison between healthcare professionals involved. Eur Medicophys 2006; 42(1): 27-36.

21. Kellerman H, Plutchik R. Emotion-trait interrelations and the measurement of personality. Psychol Rep 1968; 23:1107-1114.

22. Lamovec T, Bele-Potocnik Z, Boben D. Revised Questionnaire of Life Style and Defense Mechanisms (according to Kellerman). Ljubljana: Centar za psihodijagnosticka sredstva; 1990.

23. Grahm J, Ramirez AJ, Field S, Richards MA. Job stress and satisfaction among clinical radiologists. Clinic Radiol 2000; 55: 182-185.

24. Isikhan V, Gomez T, Danis MZ. Job stress and coping strategies in health care professionals working with cancer patients. Eur J Oncol Nurs 2004; 8(3): 234-244.

25. Vaillant GE. The historical origins and future potential of Sigmund Freud's concept of the mechanisms of defense. Int Rev Psycho Anal 1992; 19: 35-50.

26. Lazarus RS., Folkman S. Stress, Appraisal and Coping. New York: Springer; 1984.

27. De Carvalho EC, Muller M, de Carvalho PB, De Souza Melo A. Stress in the professional practice of oncology nurses. Cancer Nursing 2005; 28: 187-192.

Address for correspondence:

Kocijan Lovko Sandra

Psychiatry Outpatient Department, General Hospital Zabok, Trg D. Domjanica 6, 49210 Zabok, Croatia Tel: +385-49-221-232 Fax: +385-49-221-150

E-mail: sandra.kocijan@zg.t-com.hr 